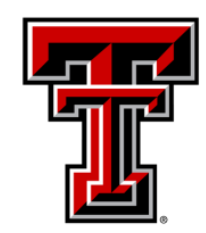

TEXAS TECH UNIVERSITY

Libraries"

\title{
WHERE DO WE GO FROM HERE? CLIMATE CHANGE AS A HUMAN AFFAIR
}

The Texas Tech community has made this publication openly available. Please share how this access benefits you. Your story matters to us.

\begin{tabular}{|l|l|}
\hline Citation & $\begin{array}{l}\text { Bradatan, C. (2013). Where do we go from here? Climate change as } \\
\text { a human affair. International Sociology Reviews, 28(5), 496-501. } \\
\text { https://doi.org/10.1177/0268580913496914 }\end{array}$ \\
\hline Citable Link & $\underline{\text { http://hdl.handle.net/2346/73737 }}$ \\
\hline Terms of Use & $\underline{\text { CC BY-NC }}$ \\
\hline
\end{tabular}


Where do we go from here? Climate change as a human affair

Cristina Bradatan

Giddens, Anthony. 2011. The Politics of Climate Change, $2^{\text {nd }}$ edition, Cambridge, Malden, MA: Polity Press, ISBN:0745655157 (pbk.), 269 pp., \$25.74

Urry, John. 2011. Climate Change and Society, Cambridge, Malden, MA: Polity Press, ISBN-13: 978-0745650371, 217 pp., \$22.38

Piguet, Etienne, Antoine Pecaud and Paul de Guchteneire (eds.) 2011. Migration and Climate Change, Unesco Publishing and Cambridge University Press, ISBN-13: 9781107662254, 464 pp., $\$ 21.96$

\begin{abstract}
Although climate change slowly emerges in the academic, media and political debates as an important social issue it might be too slow for something to change significantly before it is too late. As such, it is probably a good time for social scientists to get more involved in understanding and explaining how this entirely human affair can be tackled and how it will affect our lives. The three books reviewed here, The Politics of Climate Change by Anthony Giddens, Climate Change and Society by John Urry, Migration and Climate Change edited by Etienne Piguet, Antoine Pecaud and Paul de Guchteneire, focus all on this topic, albeit from different perspectives.
\end{abstract}

Key words: climate change, societal response, policies, migration, environmental issues Words: 3029 
Somehow unexpectedly for many of its advocates, the topic of climate change was never mentioned as such during the 2012 US presidential campaign. There were, however, instances when green energy got some attention: in the first presidential debate, the Republican candidate brought up the topic twice, criticizing the president for having spent excessively on something doomed to fail. The Republican contender, however, thought it was important to picture himself as a green energy friend rather than foe ("I like green energy as well" "I'm all in favor of green energy"). One of the planet's largest polluters, the US is painfully slow in implementing significant policies tackling the problem of climate change; the Kyoto protocol remains unsigned despite a Democrat dominated-Senate, president and - at some point - even the House.

While it is not sure what will be done by the newly reelected US president in the area of climate change, the fact that green energy became a topic of interest in a presidential debate is relevant. It highlights that environmental policies and changes have become a mainstream political concern, although a still debatable one, as it seems. In the meantime, the European Union, once a leading force in climate change politics and research, struggles to get out of the economic crisis, while developing countries such as China have become leaders in air pollution. In the media, the 'truth' or 'lack of truth' in climate change predictions is a still a hot topic and the ClimateGate affair gets brought up to life again and again, despite being already cleared up by several scientific bodies. Less than two weeks before that debate (September 18, 2012), Forbes published an article on what they called "ClimateGate Star Michael Mann Courts Legal Disaster," while Science (September 28, 2012) reported that 'climate scientist Michael Mann won an initial victory in his latest legal battle.' Meanwhile the amount of carbon dioxide in the atmosphere keeps increasing and the Arctic ice is getting thinner by the day.

Where do we go, then, from here? This review essay focuses on the idea briefly presented above: although climate change slowly emerges in the academic, media and political debates as an important social issue it might be too slow for something to change significantly before it is too late. As such, it is probably a good time for social scientists to get more involved in understanding and explaining how this entirely human affair can be tackled and how it will affect our lives. The three books reviewed here, The Politics of Climate Change by Anthony Giddens, Climate Change and Society by John Urry, Migration and Climate Change edited by Etienne 
Piguet, Antoine Pecaud and Paul de Guchteneire, focus all on this topic, albeit from different perspectives.

Giddens' book (The Politics of Climate Change) is not so much about how climate policies are defined and implemented nowadays as about how and why they should be defined in a certain way. It looks to climate change from a pragmatic and balanced rather than 'radically green' point of view. In fact, one point Giddens goes back repeatedly is that global warming should not be seen and treated as a part of the green movement policies. First of all, he says, the main focus in green movement is to protect the environment from the damage inflicted by human beings. However, tackling global warming is a way to protect human beings rather than saving the earth or protecting the nature.

Secondly, while many ideas and concepts are common to both climate change and green movements, they need to be reevaluated and discussed rather than taken for granted. The precautionary principle, a guiding concept of the green movement and one that has been incorporated into the global warming discussions is one of these ideas. The precautionary principle emphasizes safety versus risk, "better safe than sorry" rather than "he who hesitates is lost." Giddens (following Sunstein) argues that, if applied faithfully in all situations, this principle can lead to unwanted effects - for example, the intervention in Iraq can be very well explained as an application of this principle, a precautionary measure taken against a potential threat before it strikes. Therefore, policies relevant to prevent, or cope with, global warming might sometimes go against the precautionary principle. For example, the green movement is hostile to bioengineering and genetically modified crop because the long term effects of these changes are still unknown. However, coping at the same time with population growth and global warming would make the use genetically modified crop a necessity in many parts of the world. Similarly, "conservationists might resist the building of a nuclear power station, or a wind farm, in a given area of the countryside," (pp. 54) although this would not be seen as a problem for those interested strictly in global warming.

Thirdly, there is a fundamental difference between climate change and environmental problems; global warming is not visible for the layman in the same way environmental changes are:

Global change is not simply an extension of more traditional forms of industrial pollution; it is qualitatively different. Scientists, and scientists alone, have directed our attention to it, 
since it is not visible in the way London smogs were, or smoke-stack pollution is. We are also wholly dependent on the research and monitoring work of scientists to track the progress of warming and map its consequences. (Giddens, pp. 53)

While there is a tendency in the media and the general public to attribute catastrophic events, such as the hurricane Sandy, to global warming, this is not necessarily true. Certainly, such an attribution can have a positive impact on the climate change movement by exposing the climate change effects in an immediately manifest way rather than through the scientists' models. Yet, if the event is not necessarily related to climate change, it can also undermine the whole idea of climate change. Then, how can one decide whether or not a hurricane or drought is the result of climate change? Giddens (pp. 171) uses the example of the 2000 UK flooding that affected 10,000 properties to show how such claims can be scientific validated:

The researchers ran several thousand computer simulation models of the weather patterns, both under normal conditions and conditions as they might have been had greenhouse gas emissions not existed. In 90 per cent of the simulations the results showed that humanly induced global warming increased the risk of floods occurring in England and Wales by more than 20 per cent, and in two out of three cases by 90 per cent. In other words, the probability is high that the floods were influenced by climate change. (pp. 171)

While Giddens' book is focused on the current state of climate change research and policy, Urry concentrates on how our future will look like when the effects of global warming still be taken into account. As such, Climate Change and Society is an attempt to bring society back at the center of climate change analyses. Human behavior, Urry says, is primarily described by using economic models; this is also the case with climate change related discussions. Economic models are based on the assumption of the human beings as rational, individualist creatures, who take decisions based on 'economic calculation.' In any science, models are a simplification of reality and are not meant to offer an exhaustive description of what happened in the reality, yet, the main problem with economic models is that they ignore important drivers of human behavior. People 
.. do not behave as individually separate economic consumers maximizing their individual utility from the basket of goods and services they purchase and use given fixed and unchanging preferences. People are rather creatures of social routine and habit, but also of fashion and fad. The patterns of routine and fashion stem from how people are, much of the time, locked into and reproduce different social practices and institutions, including families, households, social classes, genders, work groups, schools, ethnicities, generations, nations and so on. (pp. 3-4)

How is this methodological problem relevant to the climate change discussions? Well, if we really want to understand how to tackle global warming and how to prepare ourselves for the effects that climate change will have on human communities, then we need models with a good predictive power. Since economic models do not incorporate important features of observed human behavior, it is now the time for other social sciences to get involved and develop such models if we are to address the challenging issue of global warming. Urry's book attempts to highlight exactly these 'other than economic' factors that influence human beings, which can be used to tackle the problem of climate change. One area of focus is the changing relationship between people and places and, related to this, cosmopolitanism as an important social force. Places are no longer 'places of belonging' but rather things to be experienced as tourists, 'landscape' rather than 'land'. "Collecting" places through tourism is an important component of one's social identity; yet, this was made possible with a high carbon cost. While this new relationship between people and places raises the danger of global warming, it can also be used as a way to increase awareness and push toward policies to tackle climate change. Extensive mobility creates cosmopolitanism, leads to openness toward people and places from all over the world and creates connections between people living far away. This, in turn, leads to a certain sensitivity toward environmental problems confronting global communities: a tsunami in Thailand is no longer something that affects some distant people, but something that happens in a place I traveled two months ago. Cosmopolitanism, therefore, can be used as a force to forge a large international movement and to push for global policies to tackle global warming once a shocking event due to climate change affects a part of the world:

A massive collapse of oil supply or oil price increase or dramatic flooding or drought in a global city could constitute the event that provokes such a dramatic 'climate change shock 
treatment'. This treatment would short-circuit procedures and plans and lead to the widespread top down imposition of a low carbon future. (pp. 162)

Looking to the future, Urry imagines four possible scenarios for the global society: perpetual consumerism, local sustainability, regional warlordism and low carbon, digital networks. The first (very unlikely) scenario (perpetual consumerism) is just an extension of current state of affairs, possible only if some kind of 'technological fix' occurs and decreases energy costs. While not explicitly claimed as such in Urry's description, this 'technological fix' would solve the problem of global warming in some magical way as well. Local sustainability scenario describes a global society formed by networks of self-reliant, physically semi-isolated communities 'in which people would live, work and mostly socialize.'(pp. 146) This new world would be significantly different from what we currently have and would probably be the result of a dramatic decrease in cheap energy, climate change and, as a result, social conflict. However, the same factors can also lead to a 'barbaric future,' exemplified by the third scenario (regional warlordism) in which the world would be more similar to nowadays Afghanistan, but without any US troops. The fourth scenario (low carbon, digital networks) is very much similar to the second one, with people living in small communities, carbon use much controlled and travel limited. Although he does not exclude other ideas, throughout the book Urry is more inclined to adopt the shock perspective in which the world is forced to change due to a dramatic change in cheap energy or significant environmental degradation due to climate change.

But isn't the world already going through major environmental problems that have a significant effect on people's lives? The third book reviewed in this essay - Migration and Climate Change - tries to clarify whether or not environmental changes already affect one aspect of our world society: migration. Albeit a collection of articles (edited by Etienne Piguet, Antoine Pecaud and Paul de Guchteneire), Migration and Climate Change volume succeeds in offering a comprehensive and coherent perspective on the relationship between migration and environmental changes.

Climate change is expected to have, directly or indirectly, a significant effect on human migration. The alteration of living conditions and access to food and water will enhance the risks of migration, exacerbate social conflicts, and destabilize communities. It is estimated that every year 83 million people are already affected by extreme changes in temperature, droughts and 
wildfire (Piguet et al., pp.8) and up to 250 million people will be exposed to these effects in the next 10 years (IPCC, 2007). It is easy to imagine that, when confronted with changes in climate rising temperature, sea level, and drought - whole communities will depart for more hospitable environments.

Most contributions in this book revolve around the idea of 'environmental refugee,' a concept that first appeared in the literature in the 1970s or 1980s (Gemenne, pp. 228). Although most of these environmental migrants are expected to move within the national borders, the literature is focused more on the changes in international migration due to climate changes (Koser, pp. 289). This interest results from the fact that, while for internally displaced migrants, it is rather obvious that their own government is the main institution that needs to provide support, it is not so clear what the status of an environmental migrant who migrates internationally is. As Cornil (pp. 360) points out, the refugee definition given by Geneva Convention does not include this type of situation. Extending the definition of refugee to include environmental migrants is a complicated because of "legal technical reasons, as human rights vocabulary did not sufficiently include environmental dynamics" as well as political reasons because such an "initiative would meet considerable resistance" (Cournil, pp. 366)

Another group of papers frames empirically the issue of environmentally driven migration in countries and areas such as Brazil, Nepal, Bangladesh, Nile Delta Mekong Delta and Sahel. The general idea of these studies is that the in-field relationship between migration and environmental changes is influenced by a large variety of factors such as culture, gender (Hunter \& David), income, existence of migration of networks, economic development and population growth in the region. Although migration occurs when extreme weather events such as flooding affects a region, people might not necessarily leave because of the event itself but because of other related factors, such as increasing indebtedness among Bangladeshi villagers (Findlay \& Geddes). A general idea that unifies all the studies included in this edited volume is that, while individual responses to environmental changes are not easy to predict, communities are and will be nevertheless affected and changed by them. While the research on climate change and migration as well as, generally, the social impact of climate change, is still in its infancy, each of the articles included in this edited book show that there are already many good empirical studies relating environmental problems and migration. 
Going back to the initial question of this essay, where do we go from here? How can we, as social scientists, contribute to the issue of global warming? The first two books reviewed answer unequivocally that our knowledge of human behavior and society should be used more and better in tackling this challenge for human society. We know that human behavior is complicated and rather difficult to predict using any types of models. Yet, instead of what is currently used, we should work toward developing theories and models with a better predictive power. Urry shows that we should not be afraid of imagining future scenarios just because we do not have enough data: it is better to start somewhere using knowledge that we have, rather than just leaving the field open for other sciences with less knowledge about human behavior. The third book (Migration and Climate Change) exemplifies this attitude by showing how we can contribute: while it makes sense that people confronted with stressful environmental changes would leave, this is not necessarily the case. In fact, even when they leave, they might do it not because of environmental changes, but due to the poverty that follows. Community case studies show the relationship between migration and environment changes is strongly dependent of a large variety of factors such as culture, gender, income, existence of migration of networks and population growth in the region. Because people do not behave as rational, self interested individuals, rational choice models do not have a good predictive power in this case. This is how a social scientist with a more sophisticated perspective on human beings can make a difference: by understanding and explaining the complexity of human behavior when one is confronted with significant environmental changes.

Cristina Bradatan, Assistant professor, Texas Tech University, Mail Stop: 1012, Holden Hall 158, Lubbock, Texas, Phone: 806-742-2400, Fax: 806-742-1088, e-mail: cristina.bradatan@ttu.edu

Biographical note: Cristina Bradatan works at Texas Tech University as an assistant professor of sociology and director of the Texas Tech Population Center. Her research interests are migration, society response to climate change and complex systems. 